\title{
Value-Based Process Model Design
}

\author{
Felicia Hotie $\cdot$ Jaap Gordijn
}

Received: 3 March 2016/ Accepted: 2 March 2017 / Published online: 4 October 2017

(c) The Author(s) 2017. This article is an open access publication

\begin{abstract}
Networked service value constellations, consisting of enterprises and customers working together to jointly provide a commercial service, can be analyzed from different modeling perspectives. Two such perspectives are (1) the value perspective and (2) the process perspective. Value models, describing the value perspective, indicate which economically valuable service outcomes are exchanged between the involved actors. However, a value model only shows what of economic value is exchanged, but not how this should be accomplished. Therefore, to understand a service well, an additional process model has to be designed, which shows the actual tasks to be performed by these actors as well as the time order of these tasks. A key problem is then how to construct such a process model, given an earlier designed value model. As the process model should put the value model into operation, there exists a clear relationship between both models. Previous work investigated this problem to a certain extent, but a well integrated and easy to use method is currently lacking. This paper proposes a stepwise method to design a process model for networked value constellations, given an earlier developed value model. The aim of this method is to support practitioners during the design of a process model; as a result, the proposed way of working should be tractable, well teachable, and easy to use, thereby following the same philosophy as with the $e^{3}$ value methodology, which is used to model the value perspective of networked value constellations. In addition to the stepwise method itself, the value of this paper lies also in the use
\end{abstract}

Accepted after two revisions by Prof. Dr. Zdravkovic.

F. Hotie $\cdot$ J. Gordijn $(\bowtie)$

Computer Science Department, Vrije Universiteit, Amsterdam,

The Netherlands

e-mail: j.gordijn@vu.nl of the method to explore services related to intellectual property rights (IPR) clearing.

Keywords Value model $\cdot$ Process model $\cdot \mathrm{e}^{3}$ value . BPMN · Model construction

\section{Introduction}

Commercial services are an important economic factor. In Europe, the service sector was estimated to be $71.3 \%$ of the GDP in 2015. ${ }^{1}$ Many services are in fact electronic services. These services are ordered and provisioned via the Internet (Mohan and Ramesh 2003). Examples include e-banking, software-as-a-service and electronic Intellectual Property Right (IPR) clearing, the domain of our business partner in this research.

Commercial services have economic value for the customer, therefore the customer has to pay a certain amount of money (or other compensation) to the supplier(s) of the service. Additionally, services presume a process, carried out by the supplier(s) and sometimes even by the customer. For example, a meal at a self-service restaurant requires an activity performed by the cook and by the customer.

A commercial service assumes a network of participating actors. The network contains at least one supplier and a customer, but in more complex services, many suppliers are involved to satisfy a customer need. We call such a network of actors a value constellation (Normann and Ramírez 1993, 1994).

For electronic commercial services (e.g., Spotify, Netflix, etc.), which heavily rely on information technology,

\footnotetext{
${ }^{1}$ See https://www.cia.gov/library/publications/the-world-factbook/ geos/ee.html, accessed 24 Sept 2016.
} 
the accepted way of working is to produce requirement specifications and designs in terms of conceptual models (Mylopoulos et al. 1990; e.g., UML diagrams). We consider conceptual modeling as an useful way of working; not only to understand the required information systems and business processes, but also to design and evaluate the service value proposition of a constellation of enterprises and end users in terms of a value model. Therefore, our long term goal is to contribute a model-based design method supporting the development of commercial networked service value constellations, starting at the value proposition to the customer and ending with the enabling information technology.

This paper considers two specific modeling techniques: $e^{3}$ value (Gordijn and Akkermans 2001) for understanding such service value constellations, and the quasi standard for business process modeling, the Business Process Modeling Notation (BPMN) (Owen and Raj 2003; OMG 2011) for designing business processes for constellations. Note that we have chosen BPMN for pragmatic reasons; since our findings are applicable to a wide range process modeling techniques, our contribution is agnostic with respect to the selected process modeling technique. The proposed method is also useful for value modeling techniques similar to $e^{3}$ value, such as the Resource Event Agent (REA) ontology (Geerts and McCarthy 1999).

Although they model different concerns, the $e^{3}$ value models and the BPMN models are strongly related. The $e^{3}$ value model represents actors (suppliers and customers) exchanging things of economical value (service outcomes and money) with each other. The concern here is profitability. Profitability is assessed by calculating the net cash flow for all actors involved. In order for a value constellation to be sustainable, all actors in the constellation should be able to generate a positive net cash flow. In contrast, the business process model shows how the value model is put into operation, in terms of activities, their time order, and messages exchanged. The concern here is the control flow of operational activities, as well as the assignment of these activities to actors.

A key problem while using two different modeling languages to understand different aspects of a service studied is that potentially these models may overlap, or relate in a different way, thereby exposing consistency issues. The formal consistency relationship between $e^{3}$ value and process modeling has been investigated by, e.g., Bodenstaff (2010). Another point of departure with respect to relating different perspectives on the same artifact is to consider how to derive one perspective, given the other perspective. In our case, this implies deriving the BPMN diagram, given an $e^{3}$ value diagram. However, the current state of the art with respect to deriving a process model based on a value model is rather fragmented, and a well integrated method, usable by practitioners, is lacking.

This paper proposes an easy to understand, and integrated, step-wise method to develop a process model when a value model is given, bringing together earlier developed work by a number of researchers. The aim of this method is simplicity of use; which is the same philosophy behind the $e^{3}$ value methodology. The method should be lightweight, easy to understand, and teachable, as service development projects are typically characterized by short time-to-market. We assume that the user of our method is a business development consultant with conceptual modeling skills.

To develop and validate the step-wise method, we employ the technical action research (TAR; Wieringa 2014) method. The TAR method (1) identifies a problem to be solved by a treatment (here: how to design a process model when a value model is given), (2) proposes a treatment (here: the step-wise method and (intermediate) models), (3) applies the treatment in a real-life context (here: intellectual property rights (IPR) clearing in the music industry), and (4) reflects on the treatment in the real-life context, with the aim of learning and improving.

This paper is structured as follows. First, in Sect. 2, we review the existing work on relating value models and process models, as we use this work to compose an integrated and easy to learn step-wise method to develop value-based process models. Section 3 introduces $e^{3}$ value, the technique we use to represent value models. For process models we use BPMN, and we assume the reader is familiar with this technique. In Sect. 4 we present the TAR method. Hereafter, we discuss the step-wise method for deriving a process model based on a value model. Then, we apply the proposed method to our IPR business partner. In Sect. 7, we reflect on the use of our method and suggest changes and improvements. Finally, the conclusion and suggestions for future work are presented.

\section{Designing Process Models Using Value Models}

During commercial service development in value constellations, a number of activities have to be performed, and two of them are (1) developing the value propositions (what are we actually offering to whom, and what do we request in return), and (2) designing a process that provisions the propositions (as many services are in fact processes in terms of provisioning).

The traditional way of conducting business development is rather verbose, with ideas expressed in natural language. Using natural language as requirements specification language may result in a number of well known drawbacks such as noise (irrelevant information), silence (omission of 
important information), overspecification, contradictions, ambiguity, forward references, and wishful thinking (Meyer 1985).

A conceptual model-based method would mitigate these problems, and additionally, if the method allows for a graphical specification, communication with stakeholders is easier (Wiegers 1999). Moreover, conceptual models allow for semi-automated analysis. For example, an $e^{3}$ value model (see Sect. 3 for a brief introduction) can be analyzed for a positive net cash flow for all actors involved, and a BPMN process specification can provide the groundwork for a simulation of the process at hand. Last, but not least, we argue that business development should start with a business value model, with an emphasis on model, and economic value. In many cases, business development starts with business process design immediately, thereby implicitly assuming value propositions. We claim that value proposition design should be a first class citizen in the design of service value constellations, allowing to assess promising propositions, and selecting the most interesting ones.

Taking two perspectives on a service constellation (namely a business value and business process perspective) carries the risk that both perspectives appear to be unrelated or even inconsistent with each other. To relate process models and value models, two view points can be taken: (1) considering consistency between both models explicitly, and (2) designing a process model when a value model is given, such that the process model puts the value model into operation.

Understanding consistency between both model types allows to conduct (formal) model checking between a particular value model and a process model. In Bodenstaff et al. (2007); Bodenstaff (2010), a framework is proposed to check and maintain consistency between a value model and the corresponding process oriented coordination model. The framework makes it possible to check business and coordination models on a structural model level, that is the specification of the value- and process models, but also on an instance level, namely the execution of the process in terms of a workflow management system. The notion of value model and process model instance deserves further explanation. Normally, an $e^{3}$ value model describes, for a particular time period (e.g., a year), the net value flow. Using profitability analysis, net value flow sheets can be generated. These sheets show the expected profit, based on a number of variables (e.g., number of customers, pricing formulas, etc.), and are considered as a running instance of the value model. During the same period, the process instance runs, resulting in actors exchanging objects of value with each other. The economic results of a running process instance should ideally, for a chosen time period, match with the expected profits from the value model. Although consistency checking between value and process models provides some starting points for deriving process models from value models (e.g., by considering the consistency rules themselves), it is not an explicit design method which helps consultants to develop a process model for the corresponding value model. In fact, it supposes existence of both models already, whereas the design problem is to find a suitable process model that implements a value model.

In Schuster et al. (2010); Schuster and Motal (2009), a semi-formal mapping is proposed between the $e^{3}$ value methodology, REA (Geerts and McCarthy 1999), and UMM (Huemer 2011). This method gives mapping rules, but acknowledges that sometimes mapping requires manual work.

Therefore, in this paper, we argue that creating a process model based on a value model should not be seen as a translation or (automated) mapping problem between both models only. The semantic gap between models is too large to allow for a mapping-only approach. Therefore, in our proposal, we consider the transition from a value model to a process model explicitly as a human design process.

Based on an analysis of previous work (Pijpers and Gordijn 2007a, 2008a; Weigand et al. 2006, 2007b; Wieringa and Gordijn 2005) we conclude that to transit from a value model to a process model, the following two questions should be answered:

- Do actors trust each other? (as a value model assumes a perfectly honest world)

- Is the physical possession flow of objects different from the ownership flow of objects? (as a value model only considers flow of ownership)

Trust motivations can influence the time ordering of value transfers, and therefore are of relevance to process models. For instance, a shop may require a payment in advance, before the shop actually delivers the products. We have studied trust issues extensively, see for instance Kartseva et al. (2009), and more recently Ionita et al. (2015). In order to represent solutions with respect to trust, we change the $e^{3}$ value notation in such a way that time ordering of value transfers can be represented. We call the resulting model an $e^{3}$ value trust model, as the model still only represents transfer of economic valuable objects and not topics such as message flows and control flows, which are common in process models.

The other important decision towards a process is the physical flow of value objects, and more specifically the distinction between the possession flow and ownership flow of objects. In the $e^{3}$ value methodology, we are only interested in ownership, as a value transfer implies a 
transfer of ownership of products, or the transfer of the right to enjoy an experience in case of intangible services. However, in order to transfer ownership, a different physical possession flow of objects may happen. For instance, if we order a book at a web shop, a logistic partner will be involved. That logistic partner has physical possession of the book for some time, but does not own that book. The distinction between ownership and possession of an object has been acknowledged by a number of authors. In Weigand et al. (2007a), a value object is considered as a value transformation and the right to transfer a resource, whereas for the process perspective, the physical transfer is identified, which comes close to our notion of the physical possession flow of objects. We used the distinction between ownership and possession rights as an aid to develop process models in Pijpers and Gordijn (2007b), in a method called $e^{3}$ transition. Here, ownership is defined "as the right to use and claim possession of the value object" [see also Snijders and Rank-Berenschot (2001) Pijpers and Gordijn (2007b)]. Also possession is identified as "the right to have actual (and if possible physical) possession of an object (Snijders and Rank-Berenschot 2001), but not to use the object" (Pijpers and Gordijn 2007b). We use both definitions extensively in our work. The physical flow of value objects is represented by an $e^{3}$ value possession flow model.

Since the $e^{3}$ value trust and possession flow models are just slight variations of the original $e^{3}$ value model, these variants are easy to learn, assuming that the modeler already is experienced in designing $e^{3}$ value models.

\section{The $e^{3}$ value Technique}

We briefly explain the $e^{3}$ value technique using an educational example (see Fig. 1); for a more detailed overview the reader is referred to Gordijn and Akkermans (2001, 2003).

Legal, profit-and-loss responsible entities (both endusers and enterprises) are represented as actors and market segments. An actor is a single end-user or enterprise; a market segment is a set of actors who economically value things equally and is used to state that multiple actors of the same kind exist. In the example, there are many readers who want to read a book, precisely one book store, and multiple publishers.

Actors offer value objects to and request them from their environment. A value object is of economic value for at least one actor. In the example, value objects are: books, and money. Actors request and offer value objects via value ports, thereby abstracting from how these objects are delivered, which is the focus of business process design. Ports are grouped into value interfaces, which denote economic reciprocity and atomicity. Therefore, in the model, it is only possible to obtain a book while paying for it with money, and vice versa. Note that this presumes an ideal, honest world; in other words, actors do not commit a fraud. The focus of an $e^{3}$ value model is on how value is offered, requested, and transferred in a network, and not on different kinds of deviations.

Value ports of actors are connected by means of value transfers. These represent the fact that actors exchange value objects, in the example books and money.

Finally, there is the notion of dependency path. Such a path starts with a consumer need, here the need to read a book. The actor (the reader) needs to exchange value objects via its value interface to satisfy such a need, in the example a book for money. The book store needs to exchange value objects, too, to deliver the book to the reader. In fact, the book store obtains the book from the publisher. The publisher has a boundary element, signaling that no further value transfers are considered. When to use a boundary element is a modeling decision. It could be
Fig. 1 An educational $e^{3}$ value model

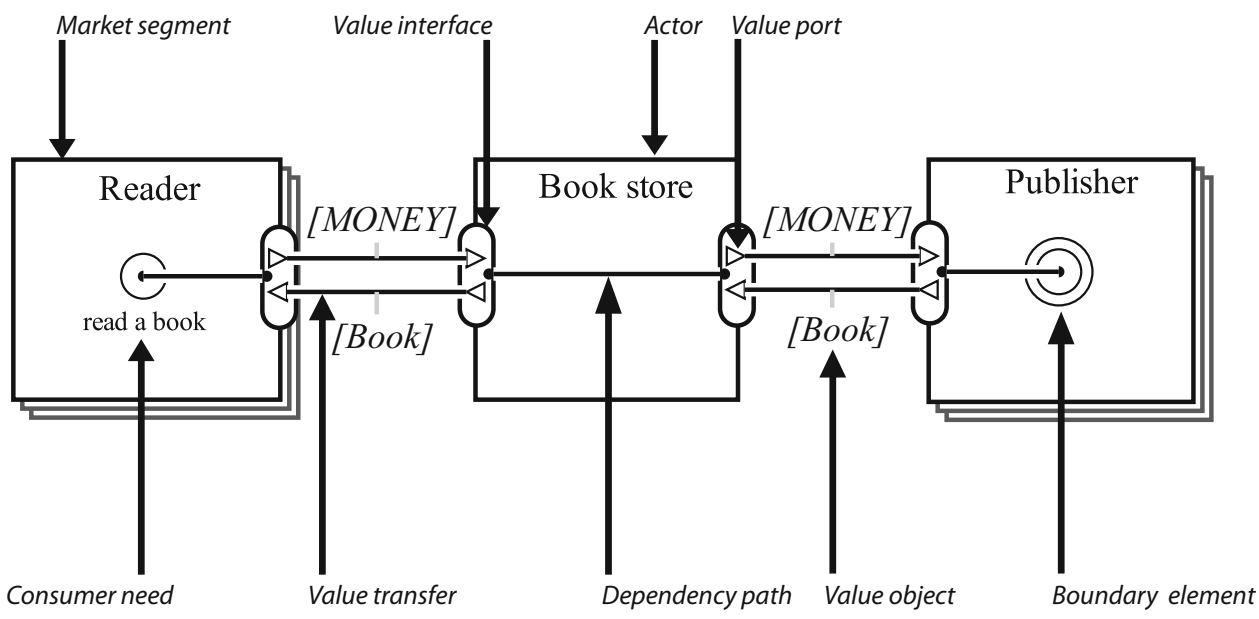


argued that the publishers need paper and ink to print the book; if the modeler wanted to express this, additional transfers would be needed.

An $e^{3}$ value model can be quantified, e.g., by stating the number of actors in a market segment, the number of consumer needs, pricing, etc. Tool support can then calculate the number of transfers, and the net cash flow for each actor involved.

There exist two other ontologically founded approaches for value-oriented business modeling: the Business Model Canvas (Osterwalder and Pigneur 2010; BMC), and the Resource Event Agent (REA) ontology (Geerts and McCarthy 1999). BMC has a single actor perspective, whereas $e^{3}$ value and REA have a multi-actor perspective. Also, BMC is informal, and therefore cannot do tool supported analysis, specifically net cash flow calculation. REA and $e^{3}$ value are quite similar although they have different origins. REA was developed as an ontology to represent the accounting domain, whereas $e^{3}$ value was exclusively designed for business development. Ontologically, $e^{3}$ value is richer in its constructs, for instance to represent dependencies between actors (dependency path), actor composition (actors having joint value propositions), multi-party ( $>2$ actors) transactions, and value activities.

\section{Technical Action Research as a Research Instrument for Design Science}

In Hevner et al. (2004), Design Science is framed as "the scientific study and creation of artifacts as they are developed and used by people with the goal of solving problems of general interest". This paper addresses the problem of finding a suitable process model for networked value constellations when a value model is given. These artifacts can be methods (in our case the way how to develop process models based on value models) as well as models [the (intermediate) models, from value model to ultimately a process model].

There exist multiple research strategies to study the above mentioned artifacts. As argued in Sect. 2, already a considerable amount of ground work has been done on designing process models by using value models. However, these works are fragmented, and an integrated method to make these works for practitioners is missing. The aim of this research therefore is (1) to develop an easy to understand, step-wise method for deriving process models from value models, which can be followed by practitioners, and (2) to test this method in a real world setting.

To learn about a method in practice, Wieringa (2014) proposes the technical action research (TAR) method. TAR specifically focuses on the artifacts (developing process models using value models, and the models themselves), rather than on the problems in general, as many other research methods do. Therefore, TAR fits our research goals, namely to develop a method to derive process models from models (the artifacts), and to do so in a reallife context. The TAR cycle comprises (1) the problem statement, to be solved by a treatment, (2) the treatment design, (3) the usage of the treatment in a real-life context, and (4) the evaluation and improvement of the treatment.

The problem this paper aims to solve is how to design a process model for networked value constellations, with a given value model as input. The goal of the method is that it is (1) model based, cf. the accepted way of working in Requirements Engineering, and (2) usable by practitioners who have modeling skills (e.g., the UML). We assume that the practitioner is capable of designing $e^{3}$ value networked business model himself; in other words, our method is not a recipe for developing $e^{3}$ value models.

In our paper, the TAR method is further used as follows. Section 5 presents our treatment design, which is the stepwise method to derive a process model based on a given value model, as well as the required intermediate models. In Sect. 6, we apply the proposed treatment to a service value constellation whose activity comprises the clearing of intellectual property rights. Finally, Sect. 7 evaluates the treatment and suggests improvements to the step-wise method.

For the real-life context, we have selected a company that works in a networked value constellation, since value models are primarily intended for designing networked business models. Our selected business partner (hereafter called the IPR society) clears IPR on music for music users (radio and television, restaurants, etc.), pays right holders (artists, producers) for the use of their music, and uses information from radio stations for doing so. Since a number of different actors are involved in this process of rights clearing, these actors form a value constellation by definition.

Regarding validation and evaluation of our method, we have deliberately chosen the process of clearing international IPR, which we know very well. The same holds for the value model. This allows us to evaluate whether our method produces a process model that is close to the known reality.

\section{Treatment Design: A Step-Wise Method to Design a Process Model Using a Value Model}

The aim of this paper is to develop a step-wise method for the design of a process model using a value model for networked value constellations, making use of the existing 
research related to this problem (see Sect. 2). As explained, two different design decisions frequently occur in the literature:

- How should one deal with (lack of) trust between actors in a networked value constellation?

- What is is the physical flow of objects in a process executed, as opposed to the ownership flow of the same object in the value model?

Our proposed treatment will be based on supporting the above mentioned design decisions. We design our treatment, the step-wise method, using an example which is easy to understand. The example networked value constellation consists of Customers, a Seller, a Carrier for handling logistics, and a Bank. The Seller is a web shop, and therefore needs a logistic provider to transport the product to the Customer. The Customer and Seller exchange a product (e.g., a book) for money, the Carrier provides a transportation service to the Seller and is paid for this, and the Bank provides payment services to the Customers and the Sellers and gets paid for service provisioning. The corresponding $e^{3}$ value model is shown in Fig. 2.

We have carefully designed this example so that the example exhibits the earlier identified two design decisions while developing a process model with a given value model:

- Trust relations may vary. For example, the Carrier may trust the Seller, since they do business on regular basis, but the Seller may not trust the Customer, because they interact only incidentally.

- The ownership flow of objects (product ownership flows from Seller to Customer) in the $e^{3}$ value model is expected to be different than the related physical possession flow in the process model (products possession goes from Seller to Carrier, and then from Carrier to Customer).

The naive approach would be to, preferably automatically, translate the value model for the example at hand into a process model. However, we argue that a value model cannot be directly translated into a process model because many different intermediate design decisions are of relevance (Pijpers and Gordijn 2007b, 2008b). For instance, the time order of the value transfers and the physical flow of the value objects are very relevant to process models, but are simply not given in a value model, as the value model shows only dependencies between value transfers, without stating whether the dependee should occur before or after the dependent.

To arrive at a process model, with a given value model, we therefore consider trust issues between actors, as well as physical flow of value objects between actors. We represent these two considerations by means of two intermediate models, namely the trust model and the possession flow model.

To keep the complexity of our step-wise method to the bare minimum, the models used to represent solutions to trust issues and the physical value flow of objects, are

Fig. 2 Value model - web shop

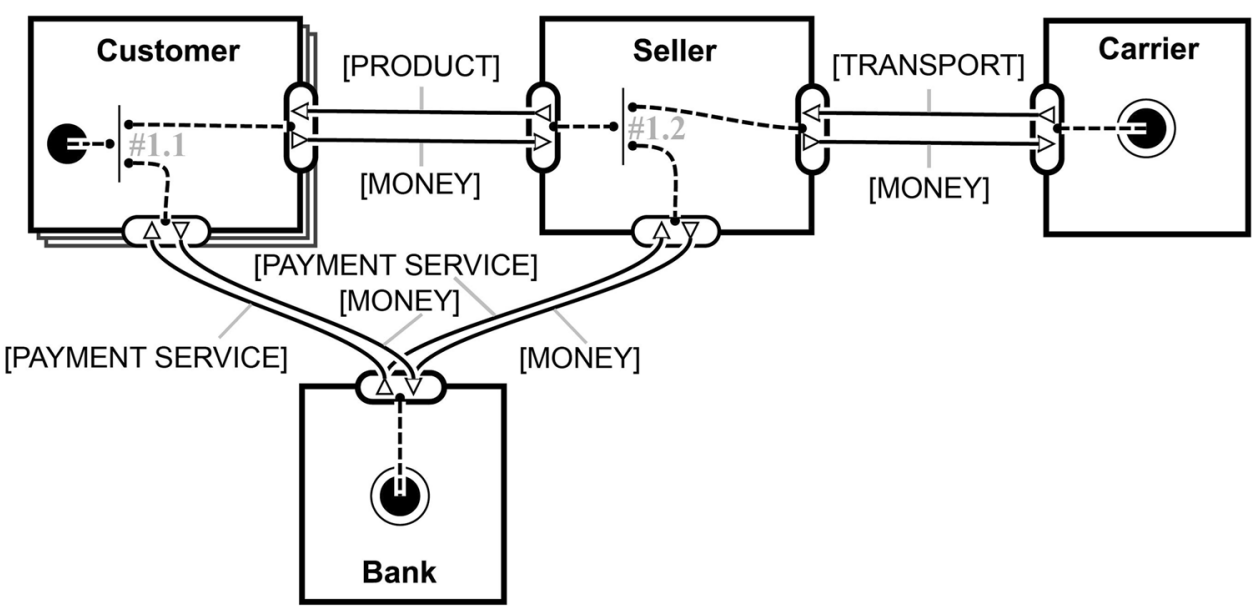

\begin{tabular}{|c|c|c|c|c|c|c|c|}
\hline \multirow{2}{*}{ Legend } & Actor & $\begin{array}{c}\text { Value } \\
\text { interface } \\
{ }\end{array}$ & $\begin{array}{c}\text { Value } \\
\text { port } \\
\nabla\end{array}$ & $\begin{array}{c}\text { Value } \\
\text { transfer }\end{array}$ & $\begin{array}{l}\text { Consumer } \\
\text { need }\end{array}$ & $\begin{array}{c}\text { AND } \\
\text { element } \\
\bullet \bullet\end{array}$ & $\begin{array}{c}\text { Explosion } \\
\text { element } \\
: \\
\end{array}$ \\
\hline & $\begin{array}{l}\text { Market } \\
\text { segment }\end{array}$ & Activity & $\begin{array}{c}\text { Value } \\
\text { object } \\
{[\ldots]}\end{array}$ & $\begin{array}{l}\text { Connect. } \\
\text { element }\end{array}$ & $\begin{array}{c}\text { Boundary } \\
\text { element } \\
\text { ( }\end{array}$ & $\begin{array}{c}\text { OR } \\
\text { element }\end{array}$ & $\begin{array}{c}\text { Implosion } \\
\text { element } \\
\text {------- }\end{array}$ \\
\hline
\end{tabular}


models that are slight, and precise articulated variations of the $e^{3}$ value models. As we assume that practitioners are already capable of developing $e^{3}$ value models, we therefore expect that these practitioners can easily learn the required variations in the $e^{3}$ value modeling language to deal with trust and possession considerations.

In sum, to create a process model, we propose to perform the following three steps: (1) create the trust model based on the inital value model, (2) create the possession flow model based on the trust model, and (3) create the process model based on the possession flow model. In the remainder of this section we discuss this step-wise method in more detail by means of the web shop example.

\subsection{Value Model}

Our step-wise method supposes a value model as a starting point. The construction of such a model is outside the scope of this work; instead we assume a suitable modeling language and methodology to construct such a value model. We use the $e^{3}$ value modeling language (Gordijn and Akkermans 2001) for expressing a networked value model.

Figure 2 shows the value model example representing a web shop with the following four economically rational actors: (1) the Customer, (2) the Seller, (3) the Carrier and, (4) the Bank. As there are multiple customers, the actor Customer is depicted as a market segment. In the $e^{3}$ value methodology, a market segment refers to a set of actors that are supposed to value things equally. The Seller may obtain the products from others, which however we consider as not in the scope of this model.

If a Customer obtains a product from the Seller, both the Customer and Seller need a paying instrument (e.g., an online bank account). This is indicated by note \#1.1 and \#1.2 in Fig. 2: it represents that in order to satisfy a consumer need, the Customer must both obtain a product and a payment service. Also, the Seller uses a payment service in order to obtain payments. Note that the value model does not show that money is actually flowing from the Customer, via a Bank, to the Seller. This will be visible in the possession flow model (see Sect. 5.3). Instead the value model shows that (1) the Customer pays the Seller (for obtaining a product), and in order to do so, (2) a payment service is required, and that the Customer and Seller pay for such a service.

Similarly, the Seller needs to obtain a transportation service from the Carrier and pays for this service. Therefore, from a logical value point of view, the Seller transfers the product to the Customer. This is despite the fact that the Carrier physically transports the product to the Customer. The reason for this is that a value model only models the value transfers in terms of ownership between the actors. The Carrier is only an intermediate actor for the Customer and there are no value transfers in terms of ownership between the Customer and the Carrier.

A key notion in $e^{3}$ value is the dependency path. This path, consisting of consumer needs, value interfaces, value transfers, connection elements, and boundary elements, shows which value transfers must happen, as a result of the occurrence of a consumer need. In Fig. 2, by considering the need, it can be seen that a product is exchanged for money, a payment service is exchanged for a payment (both for the Customer and the Seller), and that transportation is exchanged for money.

The $e^{3}$ value modeling language has a number of restrictions. Firstly, the time order of the value transfers of the involved actors on a path is not represented in an $e^{3}$ value model. The model only shows that a payment is received for a product, but not if such a payment happens before or after delivering the product. The focus is only on understanding which value transfers must happen to satisfy a consumer need, which is already sufficiently challenging in business development projects. Secondly, an $e^{3}$ value model does not allow connection elements to be located 'outside' the actors. Connection elements show the value objects the actor must exchange, as a result of other exchanges of that actor, e.g., to show that a sold product results in the need for a transportation service. Thirdly, an $e^{3}$ value model does not show the actual physical flow of the objects. Only the ownership right of the value objects are transferred in an $e^{3}$ value model. Therefore, the physical flow of a product from the Carrier to the Customer is not shown in an $e^{3}$ value model. Lastly, it is not possible to aggregate value transfers (e.g., payments) in an $e^{3}$ value model. For instance, the model states that for each use of the transportation service a certain amount of money has to be paid. What might physically happen, however, is that the Seller pays the Carrier the indebted amount of money on a monthly basis, which is aggregated amount of money for each transportation service in that month. This is not represented in an $e^{3}$ value model. In order to take into account these limitations, we create two follow-up models.

\subsection{From Value Model to Trust Model}

The first intermediate model is a so-called trust model. We create a trust model inspired by the $e^{3}$ value modeling language, but with a more extensive use of Use Case Maps by Buhr (1998). A trust model is based on the initial value model, but now shows the time order of the value transfers. The value objects are transferred following a particular time order, and in which order this happen, depends on the motivations and considerations regarding trust between the 
participating actors. The time order of value transfers varies for each organization and situation. For example, in general a customer pays in advance when purchasing a product in a web shop. However, there exist web shops that included the 'buy now, pay later' option (Mendoza and Pracejus 1997). This allows customers to pay after receiving the product(s), but requires a deposit upfront.

We assume that the actors, the value ports, the value interfaces, the value objects and the value transfers are already properly identified in a value model. Thus, we adopt these model concepts from the value model and transfer them to the trust model. It is important to understand that the value transfers remain the same, but a trust model also shows the time order of these value transfers. To do so, the connection elements of a dependency path do not connect to value interfaces (as in an $e^{3}$ value model), but connect to the value ports inside a value interface. Because value ports are used as connectors for value transfers, it is now possible to model the time order of the transfers. Additionally, a trust model allows connection elements to be located 'outside' the actors. This is in contrast with the $e^{3}$ value modeling language that only allows to use connection elements within the same actor.

We adopt the same consumer need, actors and value transfers from Figs. 2 to 3 . In this specific Web shop example we assume that the Customer pays the Seller at the point of sale. To perform this payment transaction, a payment service from the Bank is needed. Therefore the Customer pays the Seller and the Bank simultaneously (see note \#2.1). In return, the Bank provides a payment service to the Customer. Once the Seller has received the money from the Customer, the Seller obtains a transportation service from the Carrier and therefore has to pay the Carrier in return (see note \#2.2). To make the payment, the Seller pays the Carrier and the Bank concurrently (see note \#2.3). The Bank provides a payment service to the Seller in return. After the Carrier has provided the transportation service, the Seller provides the product to the Customer. Again, there is no direct transfer between the Carrier and the Customer since a trust model also represents only the value transfers in terms of ownership between the actors. Note that additional dependency paths, AND-forks and boundary elements are modeled in Fig. 3 to represent the correct time order of the value transfers.

\subsection{From Trust Model to Possession Flow Model}

The following intermediate step creates a possession flow model using the already created trust model. A possession flow model represents the physical flow of objects and is inspired by the $e^{3}$ transitionmodel by Pijpers and Gordijn (2007b). The $e^{3}$ transitionmodel shows the independent transfers of objects and their possession rights. It is possible that a value object is transferred by a certain actor, but that this actor does not have the ownership over this object (Pijpers and Gordijn 2007b). For example, a Carrier possesses a product and has to transport this product from the Seller to the Customer, but the Carrier is not the owner of the product. This transfer is called the possession transfer and is not considered as an economic value transfer, hence these possession transfers are not included in a value model and a trust model. However, these possession transfers are represented in a possession flow model. Furthermore, a possession flow model makes it possible to aggregate a number of similar value transfers for efficiency reasons, e.g., reducing the amount of transactions and/or transaction costs. For instance, all payments for a particular actor can be aggregated for a month and dealt with as one. The possession flow model of the Web shop example is presented in Fig. 4. We use the same actors in Fig. 4 as we do in Fig. 3. Note that the actor Bank appears twice to keep the possession flow model less cluttered in terms of model

Fig. 3 Trust model - web shop

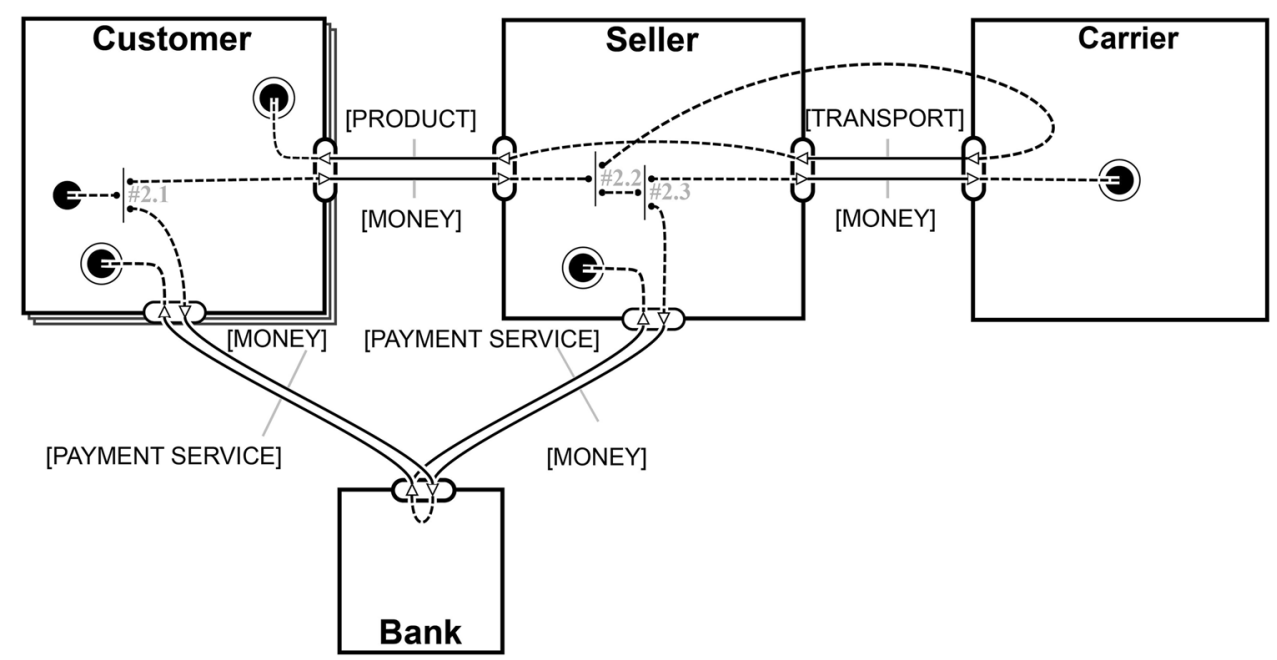


Fig. 4 Possession flow model web shop

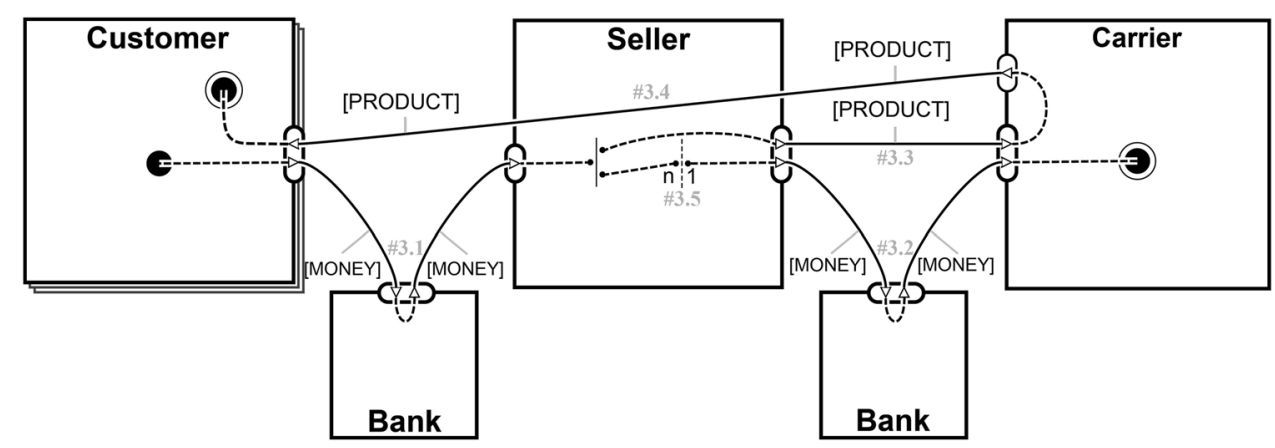

layout. In contrast to Fig. 3, we also add the possession transfers to Fig. 4.

In Fig. 4 two money possession transfers are added. The first money possession is transferred from the Customer to the Bank and from the Bank to the Seller (see note \#3.1). The Customer pays the Bank per transaction, thus the Bank keeps the transaction fee and then sends the remaining agreed amount of money to the Seller. The money possession transfer between the Seller and the Carrier proceeds via the Bank as well (see note \#3.2). Also, the Seller pays per transaction to the Bank. Note that the value transfer 'payment service' is omitted twice in Fig. 4. The money possession transfers replace this value transfer because the money possession transfers already implicitly indicate that the Bank provides a payment service to the Customer and the Seller. In this way, we avoid superfluous transfers between the actors.

In addition, two product possession transfers are depicted in Fig. 4. The first product possession transfer shows that the product is transferred to the Carrier (see note \#3.3). In this model we do not take into consideration whether the Carrier picks up the product at the Seller or whether the Seller hands over the product to the Carrier. Note that this product possession transfer replaces the 'transport' value transfer modeled in Fig. 3. The next product possession transfer (see note \#3.4) already implicitly indicates that the Carrier provides a transportation service to the Seller by showing that the Carrier delivers the ordered product to the Customer. Thus, it is unnecessary to model the value transfer 'transport' in the possession flow model. The Carrier possesses the value object at the moment, but does not have the ownership over the product. The Carrier is only responsible for transporting the product from the Seller to the Customer. The Customer is the actual owner of the product.

Finally, we model an aggregation of payments using an implosion element (see note \#3.5). The Seller pays the Carrier for multiple value transfers, in this case product transportation to $n$ customers. This avoids paying for each individual value transfer, more specifically: product transportation to only one customer. In short, the Seller pays the Carrier for $n$ transportation services in one payment.

\subsection{From Possession Flow Model to Process Model}

The final step is to create a process model, given the created possession flow model. We create the process model using the Business Process Model and Notation 2.0 (BPMN; Owen and Raj 2003). The main difference between a possession flow model and a process model is that a process model shows additional tasks that are needed to operate a possession flow model. Figure 5 shows the process model that is based on the possession flow model of our running Web shop example in Fig. 4. It is important to understand that a process model represents the same networked service as modeled in the value model, trust model, and possession flow model, but takes another perspective.

We assume that the actors, the value objects, the value transfers and OR/AND elements are already properly identified in the possession flow model. Thus, we adopt these model concepts from the possession flow model to the process model. However, the symbols of the BPMN differ from the $e^{3}$ value modeling language. Therefore we have to map the model concepts of the possession flow model to the model concepts of the BPMN. Since there are more than hundred symbols in the BPMN (Dumas et al. 2013), we will only describe the main symbols that are needed to create a process model. We describe these symbols below using our running Web shop example in Fig. 5.

Swim lanes The internal and external actors are represented as pools. These pools could either be a black box pool or a white box pool. A black box pool does not contain internal details, for example the actor Bank is represented as a black box pool. In contrast, a white box pool includes internal details and therefore gives more information about the execution of the process. In Fig. 5 there are three actors modeled as white box pools, namely (1) the Customer, (2) the Seller and (3) the Carrier. In 


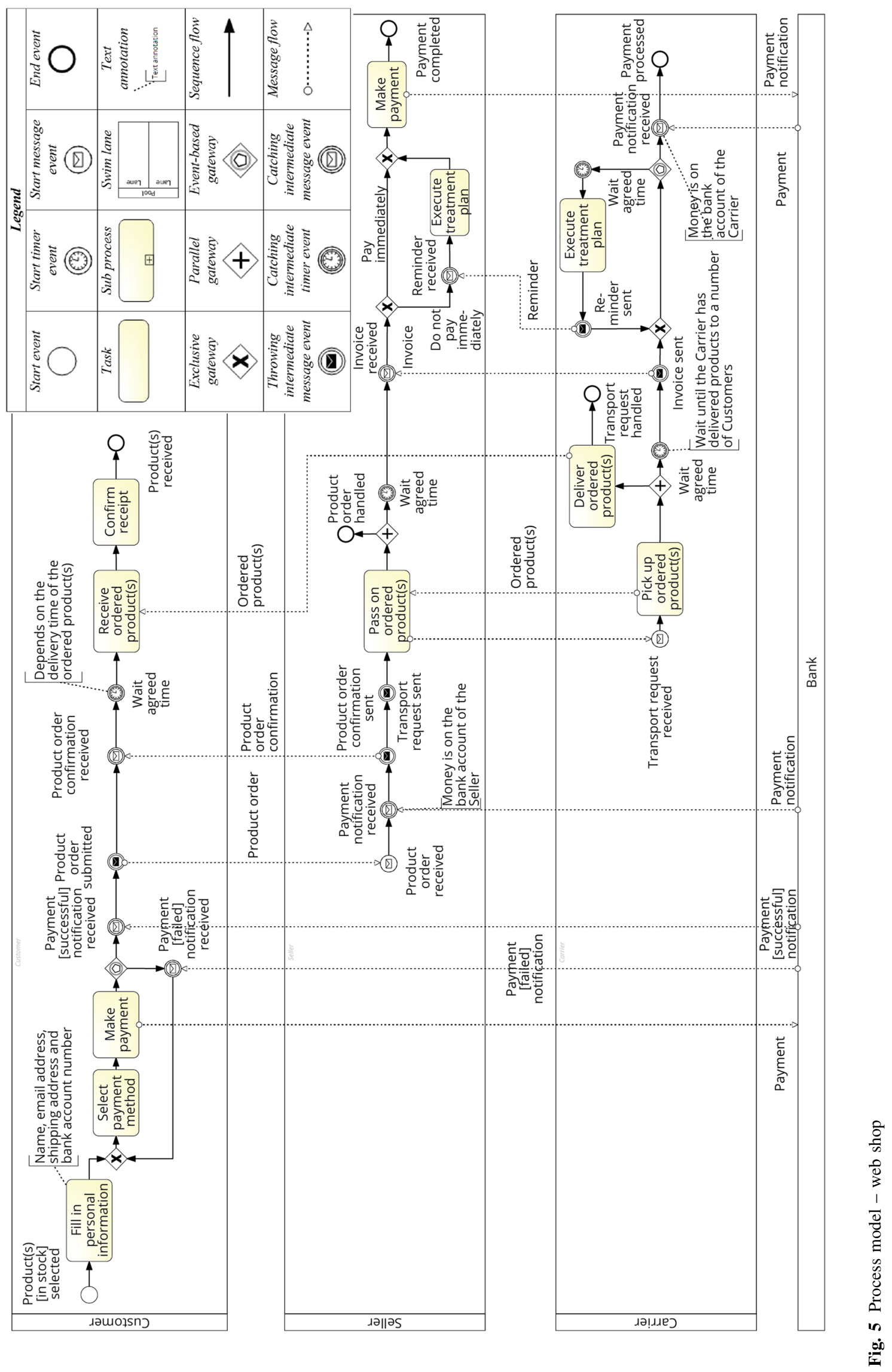


addition, white box pools can be divided into so called 'lanes' to arrange and classify the tasks within the process. For brevity, we do not further divide the internal actors in Fig. 5 (Dumas et al. 2013).

Activities Work entities with a duration are represented as tasks in a process model. It is also possible to model tasks that can be expanded, also called sub processes. The value activities, modeled in a possession flow model, can be represented as tasks in a process model. However, it is important to understand that there is a difference between value activities and process model tasks. Value activities are used to model activities that yield profit (Gordijn and Akkermans 2014), while process model tasks describe an operation. Solely value activities are not sufficient to accomplish the identified value transfers. Besides, not every possession flow model represents value activities, in particular Fig. 4. Thus, we need a number of additional tasks to put the possession flow model into operation. In order to model these additional tasks, we answer the following two questions about each identified value activity and/or value transfer: (1) which preceding tasks need to be executed to perform the identified value activity/transfer? (ex-ante) and (2) which tasks need to be executed afterwards in order to complete the identified value activity/transfer? (ex-post). Considering the Customer white box pool, we see that this actor needs to perform the following tasks in the respective order before (ex-ante) making the actual payment to the Seller: (1) select product, (2) fill in personal information and (3) select payment method. To complete (ex-post) the payment, the Customer has to receive a payment notification from the Bank that states that the payment was successful (Dumas et al. 2013).

Events Beside tasks, a process model allows to represent events as well. The difference between tasks and events is that events take place instantly in a process, so there is no duration. An event is either (1) a start event, representing the begin of the process instance (token created) or (2) an intermediate event, indicating an event that happens during a process (token on hold until the event occurs) or (3) an end event, signifying the end of the process instance (token destroyed). Two event examples are message events and timer events. Tasks that send or receive messages can be replaced by a message event. For example, the Customer submits a product order. This send task is replaced by a throwing message event 'Product order submitted'. The corresponding receive task is depicted as a catching message event 'Product order received' in the Seller lane. Next, the Customer receives a product order confirmation from the Seller. Then the Customer has to wait until the ordered product is delivered. This temporal interval is represented by a timer event. The process instance can only proceed if this timer event elapses. Every timer event depicts a catching event because the timer event elapse is outside the process' control (Dumas et al. 2013).

Gateways The already identified OR-elements and AND-elements in the possession flow model are represented as exclusive gateways and parallel gateways respectively in the process model. Both gateways can either be a split (fork) gateway (arrived tokens diverge) or a join gateway (arrived tokens merge). A split gateway has one incoming branch and more than one outgoing branches. A join gateway is the opposite of the split gateway since it contains more than one incoming branches and one outgoing branch (Dumas et al. 2013).

Connecting objects The flow objects, events, tasks and gateways, within the boundary of a pool are connected with the aid of sequence flows. Message flows are used to capture the interaction between the two different black and/ or white box pools. For instance, the following two message exchanges between two white box pools are connected via a message flow: 'Product order confirmation sent' in the Seller pool and 'Product order confirmation received' in the Customer pool. It is important to note that message flows only represent the flow of information between the different pools (Dumas et al. 2013).

\section{Treatment: International Clearing and Distribution of Music Rights}

In line with the TAR method, we now apply the treatment as discussed in Sect. 5 to a real-life context. This real-life context in question belongs music intellectual property rights (IPR) clearing and distribution of so-called neighboring rights on music. This is a networked value constellation by nature, as many different actors are involved, and therefore suitable for our purpose. Moreover, there is already detailed knowledge about the existing processes and value models relating to neighboring rights management, which allows us to validate the produced process model by applying our treatment.

Our business partner is an IPR Society who focuses on the right to make music content public. Radio stations, restaurants, shops, etc., collectively referred to as right users, make music public (e.g., they play music on their premises/on the radio) and earn money while doing so (e.g., by advertisements, creating a good shopping atmosphere, etc.). The played music has right owners, for instance artists, producers, and sing \& song writers. Right societies act as the intermediate party between right users and right owners: they collect money from music right users, and pay the collected fees to the right owners.

Our business partner, the IPR society, performs two value activities namely (1) clearance of music rights and (2) distribution of collected money to the right owners. In 


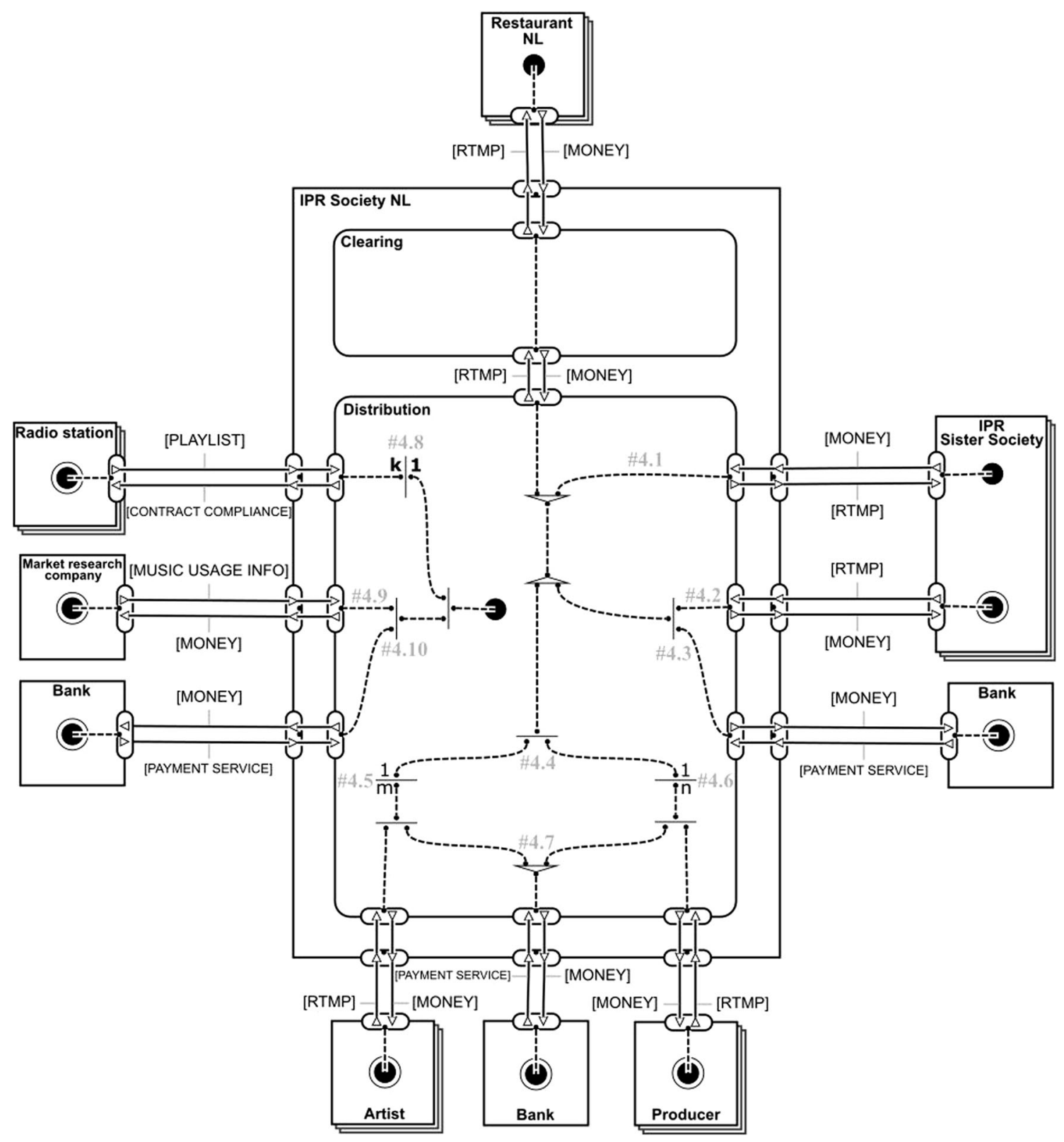

Fig. 6 Value model - IPR on music

other countries, it is also possible that two different societies perform these two tasks. Clearance implies that the IPR Society collects fees from IPR users, e.g., restaurants and radio stations, on behalf of national and international IPR owners. The IPR Society provides the right to make public (RTMP) to the IPR users in return. Distribution entails that the IPR Society divides the collected fee between the IPR owners, such as artists and producers, based on how many times a music track is played by radio stations and other entities. To obtain play-list data, the IPR Society collaborates with a market research company, radio stations and IPR Sister Societies abroad (Razavian and Gordijn 2015).

\subsection{IPR Value Model}

Razavian and Gordijn (2015) have studied the IPR e-service and created a value model for handling music rights, using the $e^{3}$ value modeling language. We extend this value model by adding the IPR Sister Society as an actor to show the international exchanges as well. Figure 6 shows the extended value model for the IPR on music. It is important to understand that this model does not show the 
time order of the value transfers, but only the causality dependency. The IPR Society ${ }^{2}$ transfers value objects to/ from the following seven actors: (1) the Restaurant in the Netherlands, (2) the Radio station, (3) the Market research company, (4) the IPR Sister Society, (5) the Artist, (6) the Producer and (7) the Bank. Note that the Bank is modeled three times in Fig. 6 because of pragmatic quality reasons (structured layout).

IPR user - the Restaurant There are multiple restaurants that play background music in the Netherlands. Therefore, the Restaurant ${ }^{3}$ actor is modeled as a market segment. The Restaurant has to clear intellectual property rights for the background music played in public. To do so, the Restaurant pays a certain amount of money to the IPR Society. In return the Restaurant receives the RTMP. Note that the IPR Society clearing activity does not exchange value objects (payment service and money) with the Bank. The Restaurant pays money to the IPR Society, thus the Restaurant has to pay the Bank for the payment service. This payment to the Bank by the Restaurant is not modeled in Fig. 6 since this value model only captures the value transfers from the perspective of the IPR Society. The music stream for the background music in the Restaurant is obtained by a background music provider, but for the sake of simplicity this actor is omitted in the value model. From a society perspective, a background music provider is treated as a Restaurant. Between the clearing and the distribution activities money and the RTMP value objects are transferred. The clearing activity gives the collected money, obtained from the Restaurant, to the distribution activity (to be discussed later).

$I P R$ Sister Society In addition, the IPR Society might obtain money from the IPR Sister Society for the international use of music (see note \#4.1). The IPR Society provides the RTMP on behalf of the Dutch Artists and Producers in return. There are a number of IPR Sister Societies, hence the actor is modeled as a market segment. The IPR Sister Society provides the RTMP on behalf of the IPR owners abroad as well (see note \#4.2). The IPR Society transfers the collected money from the IPR users in return. This payment is done per transaction via a Bank. Thus, the IPR Society pays a transaction fee to the Bank for the payment service (see note \#4.3). The IPR Sister Society divides the obtained money between the IPR owners abroad. We assume that the international distribution works the same way as the national distribution, though not modeled.

IPR owners - Artist and Producer Furthermore, the distribution activity divides the collected money over the

\footnotetext{
2 'IPR Society' refers to the Intellectual Property Rights Society in the Netherlands.

3 'Restaurant' refers to a Restaurant in the Netherlands.
}

IPR owners, in particular the Artist and the Producer (see note \#4.4). Both actors are modeled as market segments since there are numerous Dutch artists and producers. The money is divided between $m$ artists (see note \#4.5) and $n$ producers (see note \#4.6). We use this construction because usually $m$ (positive integer) artists and $n$ (positive integer) producers are involved in the production of a music track. Note that only the right holders obtain money from the IPR Society. This means that if and only if a music track of a particular IPR owner has been played in public by an IPR user, then the IPR owner obtains money from the IPR Society. For the actual payment per transaction, the Bank provides a payment service. Besides the payment to the IPR owners, the IPR Society pays the Bank a transaction fee also (see note \#4.7).

Radio station and Market research company In order to properly divide the collected money over the right holders, the IPR Society requires play lists from Radio Stations. The play lists indicate the number of times a music track has been played, thus which national IPR owners, Dutch Artists and Producers, or IPR owners abroad need to be paid. The IPR Society obtains play lists from $k$ (positive integer) important Radio Stations (see note \#4.8) yearly. As there are multiple radio stations, the Radio station actor is denoted by a market segment. A Radio Station also makes music content public and therefore the Radio Station has a contract with the IPR Society. It is part of the contract that the play list should be delivered by the Radio Station. Moreover, a Market research company provides information about the music usage (see note \#4.9) once a year. With the aid of the music usage info, the IPR Society gains more insight into the played music tracks by the IPR users (except for the Radio stations). In return the IPR Society pays money to the Market research company via a Bank. To this end, the IPR Society is charged for the use of the payment service by the Bank (see note \#4.10).

\subsection{IPR Trust Model}

The next intermediate step in the step-wise method is creating the trust model. In Fig. 7 the trust model is shown. Note that, due to lack of space, we only show a fragment of the constructed model. The interested reader is referred to Hotie (2015) for the complete model. The involved actors remain unchanged in Fig. 7, but the trust model represents the time order of the value transfers as well.

The IPR Society transfers value objects with the Radio station and the Market research company simultaneously (see note \#5.1). The IPR Society pays a transaction fee to the Market research company and the Bank in parallel (see note \#5.2). In return the Bank provides a payment service and the Market research company sends the music usage info to the IPR Society. Also, the IPR Society signs 


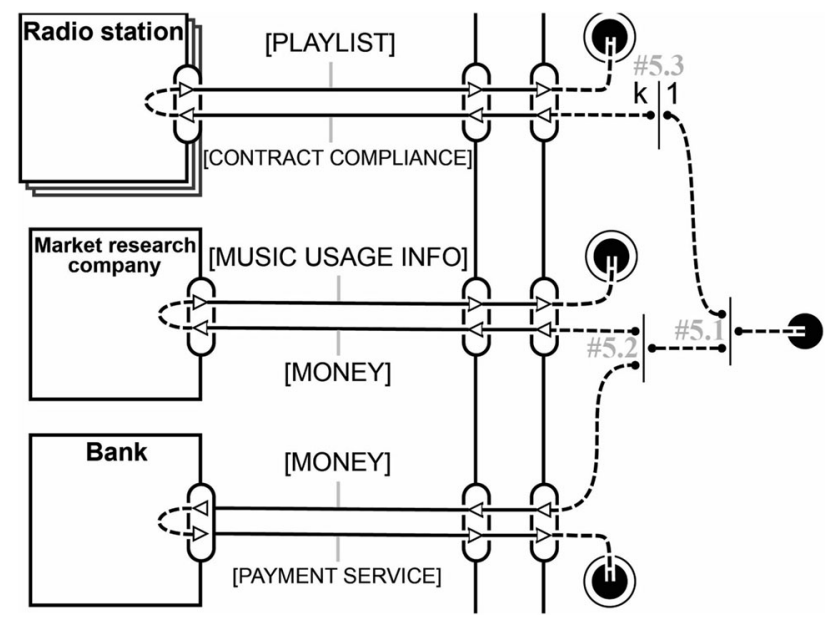

Fig. 7 Trust model - radio station and market research company

contracts with $k$ Radio stations (see note \#5.3) and in return the IPR Society receives play lists.

\subsection{IPR Possession Flow Model}

Figure 8 shows a part of the possession flow model. This model represents the physical flow of objects as well. Recall that the physical possession is not the same as ownership. Figure 8 is created using the trust model in Fig. 7. Again, the actors remain unchanged. Additionally, the money possession transfer is represented in Fig. 8. The payment from the IPR Society to the Market research company is made via a Bank (see note \#6.1).

Note that the 'payment service' value transfer is omitted in Fig. 8. For each payment service, the Bank keeps the transaction fee and then sends the remaining agreed amount of money to the respective receiving actor. In other words: the Bank provides a payment service to the IPR

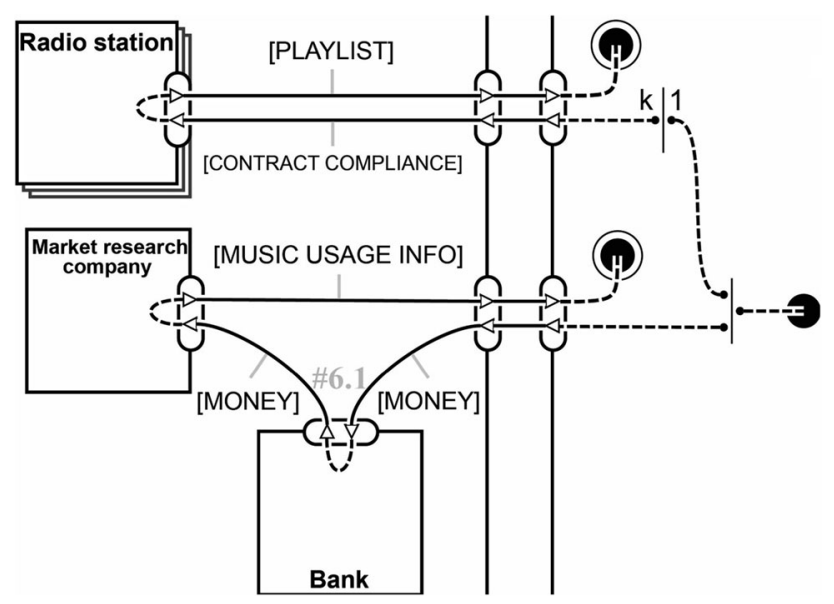

Fig. 8 Possession flow model - Radio station and Market research company
Society, even though the value transfer 'payment service' is not explicitly modeled. The other value objects, value transfers and dependency elements remain the same as in Fig. 7. A concluding remark is that aggregations of value transfers are not modeled in Fig. 8. For example, payment aggregations are not needed in this specific case since the IPR Society has an agreement with the Bank to pay per transaction, thus not for example once per month.

\subsection{IPR Process Model}

Given the possession flow model, we create three corresponding process models. We adopt the same actors, value objects, value transfers and OR/AND elements from the possession flow model to the process models. In addition to the possession flow model, the process models include additional tasks also.

Figure 9 shows the process model that is based on Fig. 8. The IPR Society, the Radio Station and the Market research company are depicted as white box pools. Another actor in this model is the Bank, represented as a black box pool. The process starts when the IPR Society needs music usage info and a play list. The process of receiving music usage info from the Market research company and the process of receiving a play list from the Radio station occur simultaneously.

In order to receive music usage info, the IPR Society has to send a request to the Market research company. Then, the Market research company sends an invoice. The IPR Society may pay immediately or not. The payment occurs via the Bank. The Market research company receives a payment notification from the Bank that states that the money is transferred. If the Market research company has not received a payment notification from the Bank within a month, then a treatment plan is executed and a reminder is sent to the IPR Society. As soon as the Market research company receives a payment notification from the Bank, the Market research company conducts the research on music usage. When the research is completed, the Market research company sends the music usage info to the IPR Society and thereby the process ends.

Also, the IPR Society sends the signed contract to the Radio stations. Note that the process of signing the contract is omitted in this model for brevity. After sending the signed contract, the IPR Society either (1) receives a complete play list, or (2) receives an incomplete play list, or (3) has received neither a complete nor an incomplete play list 1 week prior to the final delivery date. In the last case (3), the IPR Society executes a treatment plan and sends a status message to remind the Radio station that nothing has been send yet. Then again, one of the above mentioned events occur. In case the IPR Society receives an incomplete play list, the IPR Society also sends a status 


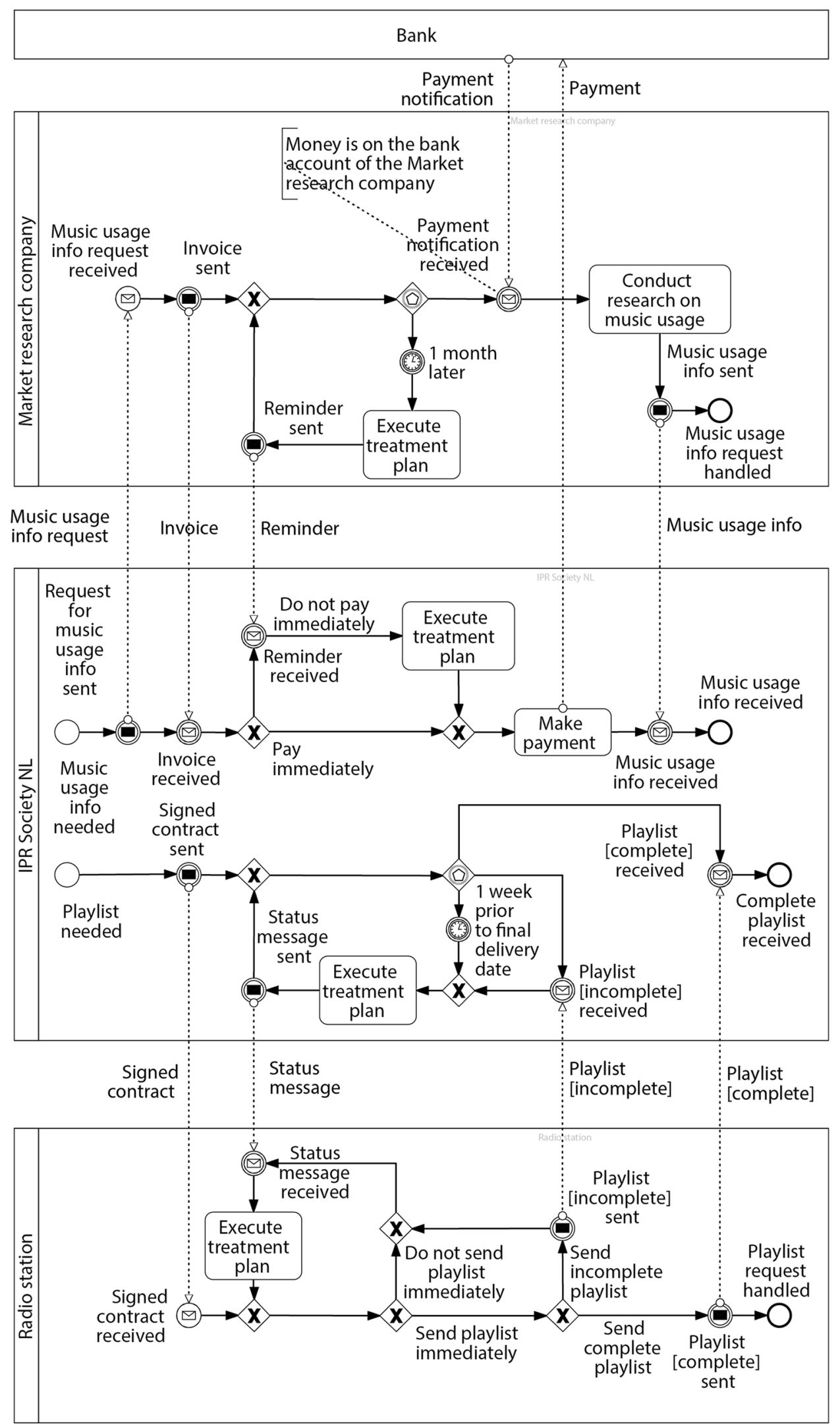

Fig. 9 Process model - radio station and market research company 
message. Finally, the process ends when the IPR Society receives the complete list, possibly after a number of iterations.

We create this process model using the provided information from the IPR employees. In other words: the Market research company and the Radio station white box pools are modeled based on assumptions from the IPR employees. To give more insight into the processes as whole, we choose to model these actors as white box pools. To maintain a minimum level of complexity for the models, we depict a number of decisions as exclusive gateways (thus explicit decisions).

\section{Treatment Reflection: Evaluation and Improvement}

The last step of the TAR method is (1) to evaluate the treatment, and (2) to improve the treatment based on this evaluation.

\subsection{Treatment Evaluation}

For treatment evaluation, we have to find out if the stepwise method to derive a process model based on value model produces an acceptable process model for the IPR society.

In order to ensure that the models provide a truthful description of the online networked services of the IPR Society, other employees of the IPR Society than the employees involved in model construction validated the models. We interviewed three IPR employees who are experts on the respective service parts. This led to a number of adjustments in the models. With the aid of the provided feedback of the one of the employees, we specified two additional timer events in the BPMN model. Timer events are hard to derive from the value model, trust model and possession flow model, as they reflect 'time outs', which are not visible in the intermediate models. Another employee validated the models regarding the IPR owners and the IPR Sister Society. This review session led to a number of detailed adjustments concerning the payments between the actors. Finally, the third employee assessed the models regarding the IPR users, in particular the Restaurant, during a conference call. After this review session, we specified a timer event label in the IPR user business process model.

This leads to the conclusion that the step-wise method is capable of deriving a reasonable first process model based on value model. However, once this process model is known it is a starting point for a more detailed specification, e.g., concerning handling requests which are not timely responded to, and for a more detailed specification of the payment process.
A further comment was that the models are on a fairly global level. For instance reminders and their follow-up actions are not modeled step by step, but are merged to form so called 'treatment plans'. We have made a trade-off between simplicity and completeness. Since complete models are often cluttered as well, we decided for simplicity and therefore uncluttered models. Note that this fits well with the philosophy of $e^{3}$ value because models that are created to explore a service are created on a relatively global level.

\subsection{Treatment Improvement}

Our proposed step-wise method makes it possible to manually derive a process model from a value model. Observations regarding the step-wise method, the results, lessons learned and improvements are discussed in the remainder of this section. Based on these observations, we can learn a number of lessons.

\subsubsection{Lesson 1: Predetermined decisions}

Observation We observed that certain actors, such as the Bank, were added at a later stage of the step-wise method. The detail level of particular actors were changed as well.

Lesson Before starting to create a model, a number of aspects need to be predetermined and remain unchanged. In this study we learned that it is important to determine in advance which actors are modeled and at what level of detail. Thus, it can be avoided to spend extra time on unnecessary things.

\subsubsection{Lesson 2: Iterative process}

Observation Until the very last end of the execution of the treatment minor adjustments were made to the created value model, trust model, possession flow model and the process models. For example, we gained new insights during the review sessions with the IPR employees and therefore we adjusted some parts of the models.

Lesson The iterative process of creating the four model types proved to be an effective method. Iteratively creating and adjusting the models enabled us to constantly compare the value model, the trust model, the possession flow model and the process models. This way, we could ensure that the models are consistent and aligned to each other.

Improvement The stakeholders mentioned that there are exceptions that have not been taken into account in the models. In order to make the models more complete by going into more detail, we could address these exceptions in a subsequent step. 


\subsubsection{Lesson 3: Processes on a global level}

Observation We deliberately created the process models on a global level because the focus was on the main tasks within the processes. The stakeholders understood the process models and were able to give useful feedback and input.

Lesson Creating the models on a global level proved to be a convenient and practical method. Only the most essential and relevant tasks should be modeled. The models do not have to be larger than necessary and not every detail has to be included. This makes them easier to understand for the stakeholders.

Improvement Additional tasks can be added as a subprocess (e.g., a sub-process model for drawing up a contract) to the existing process models. Thus, the process models are more complete and yet each model is not excessively large and complicated.

\subsubsection{Lesson 4: Number of model constructs used}

Observation To create the corresponding process model, we used a lot more model constructs in compared to the amount of model constructs used in the value model, the trust model and the possession flow model. This is intelligible since additional tasks are modeled in a process model. Yet we can conclude that this difference is considerable big, because we had to create three separate process models to represent all the required tasks for the IPR online networked services. This is despite the fact that we excluded a number of process tasks and simplified certain process parts in the process models.

Lesson Even though a process model only captures the essentials, it requires more model constructs in comparison with the other previously created models. Thus, the size difference, in terms of the used amount of model constructs, between a process model and the other created models is inevitable.

\section{Conclusion}

In this study, we proposed a step-wise method that enables to manually derive a process model from a value model. In this method the $e^{3}$ value model is the point of departure. To represent the time order of the value transfers, which is not part of the $e^{3}$ value methodology, we created a trust model. The next step in the construction of a process model is the physical possession flow of value objects. To this end, we introduced a possession flow model.

We illustrated our step-wise method with the aid of two online networked services of the intellectual property rights society, namely the right clearance and distribution over the IPR owners. The method as well as the constructed models were validated by the IPR society.

The method was tested with one elaborate field study, so further validation is needed. The method can be improved by allowing iterative development, as to our experience, value models and process models are developed side-byside rather than in a sequential process. Additionally work on model-consistency checking can be integrated with our method, to enable formal consistency checking between value models and process models in every stage.

We believe our method is usable for practitioners, although we have not validated this explicitly. All models are constructed by the researchers, in close cooperation with the IPR society, cf. the TAR method. Extensive validation of the method is a topic of research. However, the $e^{3}$ value itself has already a standing tradition and is used in the field. Since the intermediate models for trust and possession are very close to $e^{3}$ value, we expect that the method should be usable for practitioners.

Acknowledgements The authors would like to thank the IPR society for the valuable time and insights. Additionally, we are grateful to the constructive remarks of the anonymous reviewers.

Open Access This article is distributed under the terms of the Creative Commons Attribution 4.0 International License (http://crea tivecommons.org/licenses/by/4.0/), which permits unrestricted use, distribution, and reproduction in any medium, provided you give appropriate credit to the original author(s) and the source, provide a link to the Creative Commons license, and indicate if changes were made.

\section{References}

Bodenstaff L (2010) Managing dependency relations in inter-organizational models. $\mathrm{PhD}$ thesis, University of Twente

Bodenstaff L, Wombacher A, Reichert MU (2007) On formal consistency between value and coordination models. Information systems, Technical report series, no. TRCTIT-07-91. University of Twente, Enschede, The Netherlands, p 31

Buhr RJ (1998) Use case maps as architectural entities for complex systems. Software Engineering, IEEE Transactions on 24(12):1131-1155

Dumas M, La Rosa M, Mendling J, Reijers HA (2013) Fundamentals of business process management. Springer, Heidelberg

Geerts GL, McCarthy WE (1999) An accounting object infrastructure for knowledge-based enterprise models. IEEE Intell Syst $3(1): 1-6$

Gordijn J, Akkermans H (2001) Designing and evaluating e-business models. IEEE Intell Syst 16(4):11-17

Gordijn J, Akkermans H (2003) Value based requirements engineering: exploring innovative e-commerce idea. Requir Eng $\mathrm{J}$ $8(2): 114-134$

Gordijn J, Akkermans H (2014) Value webs, understanding e-business innovation. Self published. https://www.e3value.com/pub lications. Accessed 27 Sep 2017

Hevner AR, March ST, Park J, Ram S (2004) Design science in information systems research. MISQ 28(1):75-105 
Hotie F (2015) From business value models to business process models. Master's thesis, Vrije Universiteit Amsterdam

Huemer C (2011) UN/CEFACTs modeling methodology (UMM) in a nutshell 2011-04-01. UNECE, https://www.uneceorg/fileadmin/ DAM/cefact/umm/UMM_userguide-nutshell.pdf

Ionita D, Wieringa RJ, Wolos L, Gordijn J, Pieters W (2015) Using value models for business risk analysis in e-service networks. The practice of enterprise modeling. Springer, Heidelberg, pp 239-253

Kartseva V, Gordijn J, Tan YH (2009) Designing value-based interorganizational controls using patterns, pp 276-301. Vol 14 of Lyytinen et al.(2009)

Lyytinen K, Loucopoulos P, Mylopoulos J, Robinson B (eds) (2009) Design requirements engineering: a ten-year perspective. LNBIP, Springer, Heidelberg

Mendoza NA, Pracejus JW (1997) Buy now, pay later: does a future temporal orientation affect credit overuse? Adv Consum Res 24:499-503

Meyer B (1985) On formalism in specifications. IEEE Softw 2(1):6-26

Mohan K, Ramesh B (2003) Ontology-based support for variability management in product and service families. In: Proceedings of the 36th hawaii international conference on system sciences, Hawaii

Mylopoulos J, Borgida A, Jarke M, Koubarakis M (1990) Telos: representing knowledge about information systems. ACM Trans Inf Syst 8(4):325-362. doi:10.1145/102675.102676

Normann R, Ramírez R (1993) From value chain to value constellation: designing interactive strategy. Harvard business review (July-August), pp 65-77. http://eu.wiley.com/WileyCDA/Wiley Title/productCd-0471986070.html

Normann R, Ramírez R (1994) Designing interactive strategy - from value chain to value constellation. Wiley, Chichester

OMG (2011) Business Process Model and Notation (BPMN). http:// www.omg.org/spec/BPMN/2.0/PDF/. Accessed 17 Jan 2017

Osterwalder A, Pigneur Y (2010) Business model generation: a handbook for visionaries, game changers, and challengers. Alexander Osterwalder \& Yves Pigneur. Hoboken, NJ

Owen M, Raj J (2003) BPMN and business process management. Introduction to the New Business Process Modeling Standard

Pijpers V, Gordijn J (2007a) Bridging business value models and business process models in aviation value webs via possession rights. In: Proceedings of the 20th annual hawaii international conference on system sciences, Computer Society Press

Pijpers V, Gordijn J (2007b) Bridging business value models and process models in aviation value webs via possession rights. In: System sciences, 2007. hicss 2007. 40th annual hawaii international conference on, IEEE, pp 175a-175a

Pijpers V, Gordijn J (2008a) Consistency checking between value models and process models: a best-of-breed approach. In:
Johannesson P, Gordijn J, Hunt E, French X, Coletta R (eds) Proceedings of the third international workshop on business/IT alignment and interoperability (busital'08) held in conjunction with CAiSE'08 conference, CEUR-WS.org, pp 58-72

Pijpers V, Gordijn J (2008b) Consistency checking between value models and process models; a best-of-breed approach. In: CEUR workshop proceedings, Aachen. http://ceur-ws.org/Vol-336

Razavian M, Gordijn J (2015) Consonance between economic and it services: Finding the balance between conflicting requirements. Foundation for software quality. Springer, Heidelberg, Requirements engineering, pp 148-163

Schuster R, Motal T (2009) From $e^{3}$ value to REA: Modeling multiparty e-business collaborations. In: Proceedings of the 2009 IEEE conference on commerce and enterprise computing, IEEE Computer Society, Washington, DC, USA, CEC '09, pp 202-208. doi:10.1109/CEC.2009.58

Schuster R, Motal T, Huemer C, Werthner H (2010) From economic drivers to B2B process models: A mapping from REA to UMM. In: Abramowicz W, Tolksdorf $\mathrm{R}$ (eds) Business information systems, 13th international conference, bis 2010, berlin, germany, may 3-5, 2010. proceedings, Springer, Heidelberg, Lecture Notes in Business Information Processing, vol 47, pp 119-131

Snijders H, Rank-Berenschot E (2001) Goederenrecht. Kluwer, Deventer

Weigand H, Johannesson P, Andersson B, Bergholtz M, Edirisuriya A, Ilayperuma $T$ (2006) On the notion of value object. In: Dubois E, Pohl K (eds) Advanced information systems engineering. proceedings of CAiSE 2006, LNCS, 4001, Springer, Heidelberg, pp 321-335

Weigand H, Johannesson P, Andersson B, Bergholtz M, Edirisuriya A, Ilayperuma T (2007a) Value modeling and the transformation from value model to process mode. In: Morel G, Vallespir B (eds) Doumeingts G, M++ller J. Enterprise interoperability, New challenges and approaches, Springer, Heidelberg, pp 1-10

Weigand H, Johannesson P, Andersson B, Bergholtz M, Edirisuriya A, Ilayperuma $T$ (2007b) Value object analysis and the transformation from value model to process model. In: Doumeingts G, M++ller J, Morel G, Vallespir B (eds) Enterprise interoperability, Springer, Heidelberg, pp 55-65, 10.1007/978-184628-714-5_6

Wiegers KE (1999) Software requirements. Microsoft Press, Redmond, WA

Wieringa R, Gordijn J (2005) Value-oriented design of correct service coordination protocols. In: Proceedings of the 20th acm symposium on applied computing, ACM Press, New York, NY, USA, pp $1320-1327$

Wieringa RJ (2014) Design science methodology for information systems and software engineering. Springer, Heidelberg 